\title{
Are two teachers better than one?
}

\author{
M.L. van Oordt* and T. van Oordt \\ Department of Taxation, University of Pretoria, Pretoria, South Africa, and
}

\author{
P. du Toit \\ Department of Humanities Education, University of Pretoria, Pretoria, South \\ Africa
}

${ }^{*}$ Corresponding author: M.L. van Oordt can be contacted at: marius.vanoordt@up.ac.za

\begin{abstract}
Purpose - This paper aims to focus on the thinking styles of a group of Accounting students, and to determine whether team teaching by two criteria-specific lecturers can be an effective collaborative teaching approach to accommodate students' diverse learning preferences. Research on thinking and learning processes led to a four-quadrant whole-brain model of people's thinking styles and associated learning preferences. The model can be used to identify and accommodate students' diverse thinking styles and learning preferences.
\end{abstract}

Design/methodology/approach - A case study approach was followed, using multiple data collection methods. The thinking styles of 288 students and two lecturers were surveyed using a thinking style questionnaire and the Herrmann Brain Dominance Instrument. The results of the collaborative teaching approach were obtained by way of a survey questionnaire providing both quantitative and qualitative feedback, as well as a SWOT analysis completed by the involved lecturers. Findings - The main results suggest that a collaborative teaching approach can address students' diverse learning preferences, although some students may find constant switching between lecturers distracting.

Research limitations/implications - The collaborative teaching approach in the teaching interaction cannot be isolated. Collaborative teaching was not repeated or extended due to resource constraints.

Originality/value - Academics from all disciplines recognise a need for a teaching practice that addresses students' diverse learning preferences. Hitherto, outside of special education, collaborative teaching has received little scholarly attention, especially as an approach to address tertiary students' diverse learning preferences.

Keywords Education, Collaborative teaching, Dual teaching, Herrmann, Learning preferences, Team teaching, Thinking styles, Whole-brain learning, Whole-brain model

Paper type Case study

\section{Introduction}

Heywood (1874) claimed that two heads are better than one. But how effectively can this adage be transferred to the accounting education environment? It may be argued that the combined thinking styles of two people could complement each other, as described in the Herrmann Whole Brain Model (Herrmann, 1995, 1996, 1998), and that, within a particular teaching context, this may support John Heywood's famous statement.

Herrmann's thinking style theory and its associated learning preference theory form the basis of the research reported in this paper. In addition, there is an array of further 
adult learning theories that complement this theory, all based to a greater or lesser extent on the belief that learning preferences are flexible, depending on the situation, yet fairly stable over time (Coffield et al., 2004). A number of other learning theories assume that learning preferences are largely constitutionally based, are features of the cognitive structure of the learner or represent a component of a personality type (Curry, 1991). All individual learning theories are aimed at understanding the experiences of learners and are, therefore, in some way or another, related to other learning theories.

Herrmann $(1995,1996,1998)$ describes the human brain in terms of a four-quadrant model. In his model, each of the four quadrants describes a different thinking style that an individual might prefer, and the model assumes that for each person some styles are dominant, and others are secondary. Herrmann also identified the learning preferences associated with each quadrant of the model. This research has contributed considerably to the identification of a need for lecturers to facilitate learning in different ways to accommodate the various learning preferences of their students. Herrmann (1995) refers to this kind of facilitation as whole-brain teaching.

According to Bawaneh et al. (2010), a limitation in the practical application of whole-brain teaching is the difficulty of a lecturer having to adopt a teaching style different to his or her own preferred teaching style. Herrmann (1989) found that the preferred teaching style of a lecturer is directly associated with that lecturer's thinking style. Therefore, for a lecturer to accommodate all the learning preferences of students, he or she would have to adopt a teaching style that reflects all the thinking styles of students, becoming very flexible and balanced in the way that he or she facilitates learning.

Based on Herrmann's (1989) theory, it seems reasonable to argue that if two lecturers who together represent the necessary thinking styles and, consequently, teaching styles, to address all the learning preferences described by Herrmann, were to teach jointly in a team and alternate their teaching while following their preferred teaching styles, the likelihood of whole-brain teaching can be increased. Whole-brain teaching would in turn improve the understanding of the learning content by students, promote higher thinking-related energy levels in the classroom and increase higher student engagement and other indications of the promotion of whole-brain learning as a result of whole-brain teaching (Buzan, 1991; Jensen, 1996; Knowles, 1990; Ornstein, 1997).

Based on the theory of whole-brain thinking (Herrmann, 1989), the following research question was formulated, in the context of students who were following a third-year taxation curriculum, to guide the study: Can two lecturers with complementary teaching styles who collaborate as a team alternate their teaching styles during a lecture in such a way that it promotes whole-brain learning? The results of a case study to investigate this question are reported in this paper, showing how two lecturers combined their thinking styles to represent a fairly equal distribution of thinking styles, and used a collaborative teaching approach, team teaching, on a group of 288 students at a South African university.

As a matter of academic importance, this paper reports new insights for academics from different disciplines into the possibility and outcome of a practical approach to address the different learning preferences of students, namely, collaborative teaching, which could contribute to the optimisation of teaching and learning, as called for by Slabbert et al. (2009). 


\section{Learning theories}

Learning theories can be grouped into four broad categories. The first of these categories contains theories that assume that learning styles are largely constitutionally fixed, with characteristics that can be fairly easily modified by the learner's environment (Coffield et al., 2004). Dunn and Griggs (1998, p. 3), for example, state that learning styles are a "biologically and developmentally imposed set of characteristics that make the same teaching method wonderful for some and terrible for others". Theories considering cognitive styles related to specific areas of the human brain (Geschwind and Galaburda, 1987; Springer and Deutsch, 1989) can also be included in this category.

The second category refers to theories regarding "structural properties of the cognitive system itself" (Messick, 1984, p. 60). Theories in this category see learning styles as habits of thought which provide an enduring structural basis for learning styles (Messick, 1984). The research of Witkin (1962) and Kagan (1966) forms much of the foundation of cognitive system-related learning theory.

The third category of learning theory is primarily influenced by the work of Jung (1968). It links a person's learning style to a relatively fixed personality type. The theorists in this category embed learning styles within an understanding of specific personality traits (Grigorenko and Sternberg, 1995; Jackson, 2002; Myers and McCaulley, 1985).

In the final learning theory category, learning styles are not seen as a fairly fixed trait, as is the case in the previous categories, but rather as a learning preference that differs between individuals and situations (Kolb, 2000). The main models and instruments that have contributed to the theories in this category are Kolb's Learning Style Inventory, Honey and Mumford's Learning Styles Questionnaire, Allinson and Hayes's Cognitive Style Index, Herrmann's whole-brain model and the Herrmann Brain Dominance Instrument (HBDI; Coffield et al., 2004).

After reviewing Herrmann's whole-brain model and the HBDI and its use within education, Coffield et al. (2004, p. 84) reported that this model:

[...] although largely ignored in academic research, offers considerable promise for use in education and training. It is more inclusive and systemic than many others, taking an optimistic, open and non-labelling stance towards the development of people and organisations.

The strengths of the model outweigh its weaknesses - the main weakness is a lack of academic research relating to the use of this model for educational purposes (Coffield et al., 2004). This study explores the application of the model because of the promise it offers and the lack of prior academic research cited by Coffield et al. (2004).

\section{The Herrmann whole-brain model and associated thinking styles and learning preferences}

The Nobel Prize winning research conducted by Sperry in developing the "Split Brain Theory" and the identification of the brain's three sub-entities by MacLean in the "Triune Brain Theory" are combined in Herrmann's whole-brain model (Herrmann, 1995; Ornstein, 1997). The four quadrants of this model represent cognitive predilections, resulting in different thinking styles among individuals (Herrmann, 1995) (Figure 1).

As Figure 1 illustrates, diverse thinking styles are detailed in the different dominant quadrants of Herrmann's whole-brain model. As a result of these thinking styles, a 


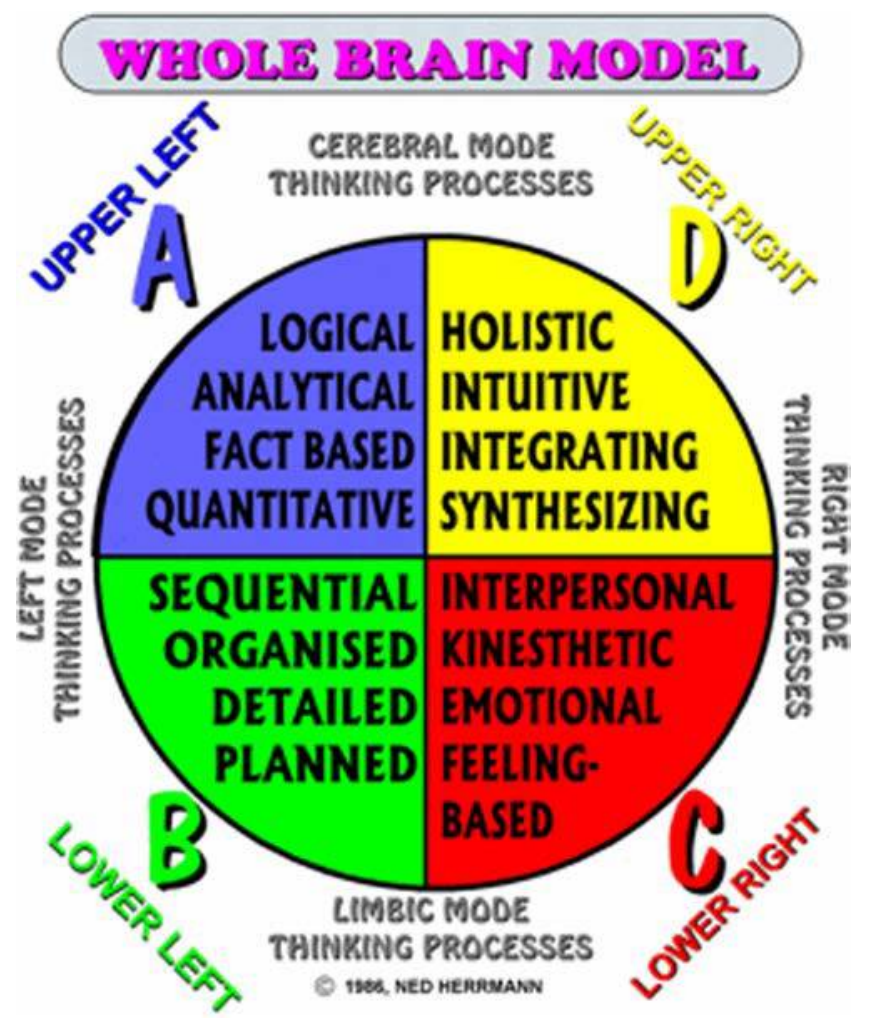

Source: Herrmann (1996, p. 30)

Figure 1. Herrmann's whole-brain model

student develops a preferred way of learning, referred to as the student's learning preference. These learning preferences are summarised in Figure 2.

When a lecturer facilitates learning in a manner that addresses all the thinking styles presented by the four quadrants of the model (Figure 2), the lecturer facilitates whole-brain learning. Each of the four quadrants is therefore involved in learning, resulting in a better understanding of content, higher thinking-related energy levels in the classroom, an overall increase of learner engagement and numerous other indications of effective learning (Buzan, 1991; Jensen, 1996; Knowles, 1990; Ornstein, 1997).

Although Herrmann's whole-brain model is well-established in the business world, its practical application has not yet been extensively researched in general education (Coffield et al., 2004). Shelnutt et al. (1996) have conducted research to establish the thinking styles of a group of engineering students based on Herrmann's research. This research reported a fairly equal spread of students' thinking styles, although these students tended to prefer the $\mathrm{A}$ and $\mathrm{B}$ quadrants slightly to the $\mathrm{C}$ and $\mathrm{D}$ quadrants. Similar results were obtained in a study by De Boer and Berg (2001) conducted on Bacteriology students at the University of Pretoria, South Africa, showing an equal spread of preferences in all four quadrants. De Boer and Steyn (1999) measured the 


\begin{tabular}{|c|c|}
\hline $\begin{array}{l}\text { A Learns by: } \\
\text { - Acquiring and quantifying facts } \\
\text { - } \text { Analysis and logic } \\
\text { - } \text { Thinking through ideas } \\
\text { - } \text { Forming theories }\end{array}$ & $\begin{array}{l}\text { Learns by: } \\
\text { - Taking initiative } \\
\text { - Exploring hidden possibilities } \\
\text { - Relying on intuition } \\
\text { - Constructing concepts } \\
\text { - Synthesising content }\end{array}$ \\
\hline $\begin{array}{l}\text { B Learns by: } \\
\text { - Organising and structuring } \\
\text { content } \\
\text { - Evaluating and testing theories } \\
\text { - Practice } \\
\text { - Implementing theories }\end{array}$ & $\begin{array}{l}\text { C Learns by: } \\
\text { - Listening and sharing ideas } \\
\text { - Integrating experiences with self } \\
\text { - Moving and feeling } \\
\text { - Emotional involvement } \\
\text { - Harmonising with content }\end{array}$ \\
\hline
\end{tabular}

Source: Herrmann (1996, p. 154)

Figure 2. Learning preferences based on thinking styles

thinking styles of students who did not fulfil the admissions requirements to the University of Pretoria. The results indicated dominant A and B quadrant thinking styles among these students.

Most of the prior research has focused on determining the thinking styles of a group of students. By contrast, the study reported in this paper aims, first, to determine the thinking styles of students, and second, to investigate a teaching approach to accommodate the diverse thinking styles and consequent learning preferences of students.

If a lecturer wishes to accommodate the learning preferences of his or her students, it stands to reason that the lecturer needs knowledge about those students' thinking styles and associated learning preferences. It is further suggested that lecturers acquire insight into their own thinking styles and the implications of their preferences for their teaching practice. Thinking styles can be measured using the HBDI, which has been shown to be a valid and reliable instrument for measuring human thinking styles (Bunderson, 1995) and which provides a testee with a thinking style profile (Figures 3 and 4). This instrument can be used to determine whether lecturers need to change or adjust their preferred teaching styles.

\section{Changing teaching styles}

The findings of Gardner and Hatch's (1989) study on Gardner's theory of multiple intelligences and the implications thereof for the educational environment are in line with Herrmann's argument that individual thinking styles are reflected in learners' diverse preferences when learning. Furthermore, lecturers should consider these diverse preferences to ensure a teaching practice that meets the learning needs of any group of students optimally (Coffield et al., 2004).

Herrmann's research has revealed two factors that can be used to determine whether a lecturer needs to change his or her teaching style: first, the learning preferences of the 


\begin{tabular}{r|c|c|c|c|} 
Quadrant : & A & \multicolumn{1}{c}{ B } & \multicolumn{1}{c}{ C } & \multicolumn{1}{c}{ D } \\
\cline { 2 - 5 } Preference Code & 1 & 1 & 3 & 2 \\
\cline { 2 - 5 } Adjective Pairs : & 11 & 8 & 0 & 5 \\
\cline { 2 - 5 } Profile Scores : & 132 & 89 & 23 & 47 \\
\cline { 2 - 5 }
\end{tabular}

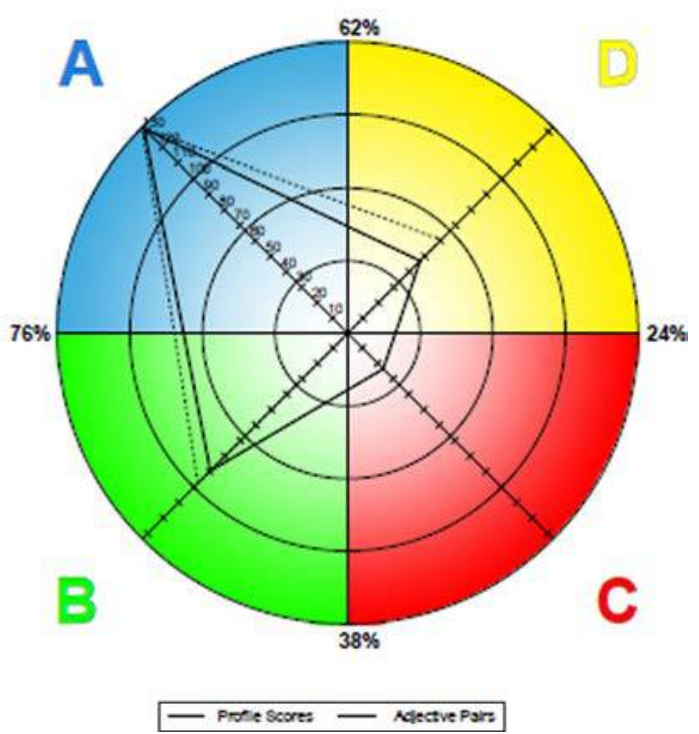

Figure 3. Results of the HBDIs completed by Lecturer 1

students and, second, the thinking style of the lecturer. With regard to the learning preferences of students, Herrmann (1996, p. 151) claims that "[e]very classroom represents a complete spectrum of learning [...] preferences". The research cited above that was conducted at the University of Pretoria supports this argument, and found that, irrespective of the module in which a group of students specialises, that group of students represents an equal distribution of thinking styles (De Boer et al., 2001). A lecturer could, therefore, make the reasonable assumption that to optimise his or her teaching practice, he or she should adopt a teaching style that accommodates all the possible learning preferences described by Herrmann (Figure 2).

In respect of teaching style, Trigwell et al. (1999) argue that there are two broad teaching approaches. The first approach is an information transmission-focused or lecturer-focused approach. This approach is preferred by lecturers who display a preference for the $\mathrm{A}$ and $\mathrm{B}$ quadrants of thinking. The second approach is a conceptual change-focused or student-focused approach. This approach is mainly preferred by lecturers who favour the $\mathrm{C}$ and $\mathrm{D}$ quadrants of thinking (De Boer and Bothma, 2003). 


\begin{tabular}{r|c|c|c|c|} 
Quadrant : & A & B & C & \multicolumn{1}{c}{ D } \\
\cline { 2 - 5 } Preference Code : & 3 & 2 & 1 & 1 \\
\cline { 2 - 5 } Adjective Pairs : & 1 & 4 & 12 & 7 \\
\cline { 2 - 5 } Profile Scores : & 29 & 60 & 119 & 95 \\
\cline { 2 - 5 }
\end{tabular}

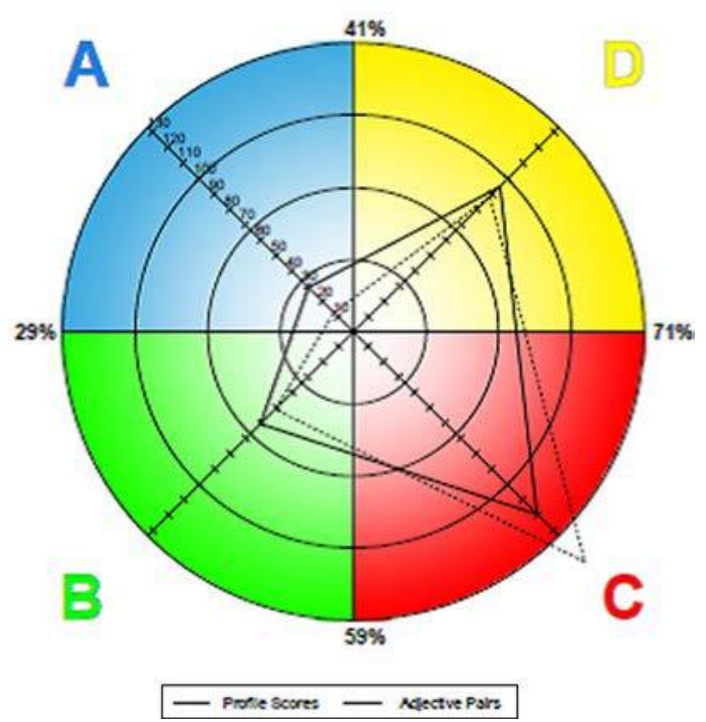

Figure 4. Results of the HBDIs completed by Lecturer 2

Extensive planning and practice could assist a lecturer to adjust his or her teaching style, but there is a direct relationship between the thinking style of a lecturer and that lecturer's preferred teaching style (Herrmann, 1989). This means that lecturers prefer to teach content in the manner in which they construct meaning regarding the content. This poses a challenge for lecturers who wish or need to accommodate all the learning preferences of their students, as the lecturer's preferred teaching style needs to be adjusted to not only reflect the lecturer's own thinking style, but rather all the thinking styles as described by Herrmann (De Boer and Bothma, 2003).

Most lecturers do not have a teaching style that can accommodate the learning preferences of all their students, and most need to undergo some professional development interventions to adjust their teaching style, do extensive planning of learning opportunities to implement the adjusted teaching style and practise this adjusted teaching style over an extended period (Hyman and Rosoff, 1984).

By attending to their own actions teachers [lecturers] will focus on what they can control. The learning, practicing, and utilising of a variety of teaching strategies will give teachers [lecturers] a sense of efficacy in the classroom. Being knowledgeable and skilful regarding 
their own actions - what they do, control, and are responsible for - is a requisite for teachers [lecturers] being able to match learning preferences with teaching styles (Hyman and Rosoff, 1984, p. 41).

Therefore it seems evident that to optimise their teaching practices, lecturers need to adjust their teaching styles to accommodate the learning preferences of their students.

Various challenges may prevent a lecturer from changing or adjusting his or her teaching style (Dunn and Dunn, 1979). Obtaining the necessary knowledge regarding methods and styles of facilitating learning may require time, which a busy lecturer may not have, if the lecturer has to deal with high student:staff ratios, high teaching loads, assessment and research demands. The practical application of different methods and styles of facilitating learning may even require further professional development in this regard. In addition, many lecturers may not be able to muster the level of commitment required over an extended period continually to incorporate different methods of facilitating learning. To reduce the challenges of adjusting lecturers' teaching styles, in this study, a collaborative teaching approach was developed with two lecturers to promote whole-brain learning.

\section{The collaborative teaching approach}

Collaborative teaching refers to a teaching approach where lecturers work in a coactive and coordinated manner to teach academically jointly (Gerber and Popp, 2000). "Two or more professionals jointly deliver substantive instruction to a diverse, or blended, group of students in a single physical space" (Cook and Friend, 1995, p. 1). This teaching approach steps away from isolated teaching practice, and introduces collaboration between two lecturers, ideally in all facets of the educational process (Cook and Friend, 1995).

The collaborative teaching approach is most commonly associated with a service delivery option in special education. Much of the literature reports on successful collaborative teaching programmes delivered to students with disabilities, incorporating the combined efforts of a general and a specialised educator (Adams and Cessna, 1991; Howell, 1991; White and White, 1992). These programmes reveal some of the benefits of collaborative teaching, such as an increased number of instructional options for students, improved programme intensity and continuity and the combination of the strengths of two educators who have different kinds of expertise and knowledge, allowing them to meet students' needs better (Bauwens et al., 1989; Cook and Friend, 1995; Walsh, 1992). According to Robinson and Robert (1995), there are also benefits for lecturers in using collaborative teaching, such as improving the selection and structuring of course content, offering more creative and diverse learning opportunities and methods of facilitating learning and increasing ways of actively involving students in the learning process. However, other studies have explored the limitations of and problems with adopting and following a collaborative teaching approach (Fuchs and Fuchs, 1992; Pugach and Johnson, 1995; Reeve and Hallahan, 1994), such as students' perplexity at having two lecturers, lecturers' resistance to changing their teaching techniques and conflict between lecturers regarding ideas.

Collaborative teaching can take many forms, such as "One Teaching - One Assisting", "Station Teaching", "Parallel Teaching", "Alternative Teaching" or "Team Teaching". In exploring the research question of this study and combining the thinking styles of the two lecturers, it was essential that the lecturers alternate their teaching and 
that the teaching load be equally shared between them. It was further important that a single concept be explained or discussed by both lecturers; otherwise all the learning preferences of students would not be addressed for this concept (a requirement for whole-brain learning).

After considering the various collaborative teaching models, it was found that only team teaching provides for a shared approach to facilitating the learning where the teaching load can be shared and a single concept can be discussed by both lecturers. In the team teaching model, lecturers take turns leading the discussion and add to, agree with or provide different opinions on the discussion (Cook and Friend, 1995). For these reasons, team teaching was chosen as the collaborative teaching model for this study. Within the team teaching model, the suggestions for effective collaborative teaching as described by Robinson and Robert (1995) were also referred to. These include restricting the teaching team to two lecturers, selecting and structuring course content that appeals to both lecturers and discussing the differences regarding their teaching philosophy and methods of facilitating learning with one another.

To use the collaborative teaching approach of team teaching, with a view to promoting whole-brain learning, in line with Cook and Friend's (1995) study, the lecturers together needed to accommodate the array of learning preferences represented among a specific group of students. It was assumed, based on Herrmann's (1995, 1996, 1998) research, that the preferred teaching style of each lecturer is directly related to the thinking style of that lecturer. The preferred teaching style of a lecturer is, therefore, likely to be most accommodating to a student with a learning preference associated with the thinking style of that lecturer. That is, a lecturer with a preference for A and B quadrant thinking and an associated teaching style would be most accommodating to a student with a complementary learning preference, namely, a preference for A and B quadrant thinking. To address all the learning preferences of a specific group of students, a combination of the lecturers' thinking styles, which should represent an equal distribution of the four quadrants, should therefore, based on Herrmann's (1989) theory, accommodate all the students' learning preferences, resulting in whole-brain learning.

To examine the practical application of a collaborative teaching approach, a case study was conducted by presenting one lecture (incorporating the collaborative teaching approach) to a group of 288 third-year Accounting students.

\section{Research approach}

In view of the research question, it was decided that a case study would be an appropriate research approach. A case study is concerned with research that is empirical, about a particular case, focused on the phenomena in context, with multiple methods of data collection (Robson, 2011). The particular case can be concerned with, among other things, a person, a group of people, an event or an idea (Robson, 2011). The evidence may be qualitative (e.g. words), quantitative (e.g. numbers) or both.

For the purposes of the study, a case study approach was conducted on a collaborative teaching event. To gain insight into the effectiveness of the collaborative teaching approach in addressing the learning preferences of the students, data were collected by means of a questionnaire, providing both qualitative and quantitative feedback. The observations of the lecturers were also recorded by means of a SWOT 
(Strengths, Weaknesses, Opportunities and Threats) analysis, as recommended by Morrison (2005).

It is acknowledged that examining the lecturers' teaching style and the learning content separate from the various complex aspects of a teaching and learning interaction (Wood, 1991) does pose a number of theoretical and methodological problems. For instance, a participant's amount of sleep the previous night was not taken into account in the research, but might well have influenced that participant during the study. The thinking and learning preference of a participant may not be accurately established, or the participant may not be as fully involved in the research as would be desirable. Various other potential elements, many of which cannot be controlled, can contribute to or influence results. Furthermore, as all learning theories are in some way related to another, it may be possible that other approaches to facilitate learning are being adopted, besides the collaborative teaching approach. Moreover, the collaborative teaching approach has received very little scholarly attention outside of the sphere of learners with special education needs, and this lack of research imposes further limitations on the successful implementation of this teaching approach. However, despite the possible influence of such factors on the results, the case study as executed did, in the opinion of the researchers, provide some insightful results.

The research approach is described in four phases. Phase I outlines the criteria and processes involved in selecting the lecturers who implemented the collaborative teaching approach during the learning opportunities. Phase II describes the criteria for the selection of the student participants in the case study. Phase III describes the chosen lecturers' preparation for the learning opportunities. Phase IV discusses the structure and implementation of the learning opportunities.

\subsection{Phase I: selecting the lecturers who would participate}

The criteria for the selection of the lecturers who would implement the collaborative teaching approach were largely based on the literature (Cook and Friend, 1995; Herrmann, 1989, 1995; Robinson and Robert, 1995). To explore the research question, the researchers had to ensure that, together, the thinking styles of the two selected lecturers represented a fairly equal distribution across the four quadrants described by Herrmann.

Furthermore, the chosen lecturers had to be regarded as equally competent by students. It stands to reason that a lecturer whom students regard as incompetent is unlikely to accommodate all the learning preferences of students satisfactorily. Moreover, if one lecturer is regarded as more competent than the other, the results of the study, particularly regarding the preference of lecturer by students, could be skewed.

To meet these criteria, the HBDI was completed by two lecturers who, in their own opinions, differed significantly in their teaching styles. These lecturers reported that the first lecturer (referred to as Lecturer 1) seemed to follow a transmission-focused or lecturer-focused teaching style, while the second (referred to as Lecturer 2) seemed to follow a conceptual change-focused or student-focused teaching style, as described by Trigwell et al. (1999). Student feedback which formed part of the performance management of lecturers at the university where the lecturers work was obtained from the university's IT-Systems department. The lecturers met the required criteria (see the discussion of results in Section 7.1). 


\subsection{Phase II: selecting student participants}

Robinson and Robert's (1995) suggestion was followed in selecting the participants for such a case study: first, the group of students had to follow a module of which both the chosen lecturers had extensive knowledge, as both lecturers had to be comfortable with the content of the learning material. Moreover, based on Herrmann's $(1989,1995)$ theory, the participants had to represent a balanced distribution of thinking styles to ensure that the promotion of whole-brain learning was indeed required. Finally, to increase the validity of the results and decrease bias of students towards one lecturer, it was ascertained that none of the students knew either of the lecturers personally, or had previously attended a lecture offered by him or her.

The group of participants who met these three criteria consisted of 288 English-speaking third-year students registered for a taxation module and majoring in Accounting. A filtering question on the data-collection instrument was used to ensure that none of the students knew either lecturer personally or had previously attended a lecture by one or both of the lecturers. Both lecturers were very familiar with the content of the lecture, namely, income tax exemptions and deductions.

The thinking styles of the 288 students were determined by means of a thinking style questionnaire (TSQ), based on the HBDI. The TSQ is a shorter version of the full HBDI questionnaire and was chosen because of time and budget constraints. The questionnaire consists of 24 statements on thinking and learning preferences, and the students were required to indicate on a 5-point Likert scale (ranging from strongly disagree to strongly agree) to what extent they agreed with each statement. As in the case of the HBDI, the results of the questionnaire indicate each student's thinking style and associated learning preferences in terms of the four quadrants described by Herrmann. The TSQ proved to be sufficiently accurate for its purpose within the scope and aim of the study (see the results discussed in Section 7.2).

\subsection{Phase III: preparing for the lecture}

As discussed in the literature review, the case study investigated the practical application of a collaborative teaching approach and whether the combination of the preferred teaching styles of two lecturers could accommodate all the learning preferences of the group of students. It was therefore important that each lecturer taught in a manner that reflected his or her own preferred teaching style (the results discussed in Section 7.3 suggest that they did so). The lecturers prepared individually in the same manner as for their usual lectures, with the focus on teaching only in terms of their preferred teaching style. The content of the lecture to be prepared consisted of the revision of previously taught topics, and some new content.

To eliminate the risk that a rehearsal could influence the teaching styles of the lecturers, based on new knowledge or views gained on the content from hearing the other lecturer, the lecture was not rehearsed, although, as suggested by Robinson and Robert (1995), the lecturers discussed their teaching philosophy and methods of facilitating learning before presenting the lecture.

\subsection{Phase IV: the lecture and reflection on it}

Before the lecture commenced, the students were required to complete the TSQ (see Phase II). During the lecture, the two lecturers followed the team teaching model (Cook 
and Friend, 1995) and also taught, to the best of their ability, according to their preferred teaching styles.

After the completion of the lecture, the students were asked to complete the data-collection questionnaire. The first part of the questionnaire contained statements concerning the lecture and the lecturers, requiring each student to indicate on a 5-point Likert scale to what extent he or she agreed with each statement. To determine whether there was any relationship between the quadrant score of a student (see Phase II), and any one of the options presented by the Likert scale, the Kruskal-Wallis one-way analysis of variance test was used. A statistically significant result on this test indicates that the higher the score on a specific thinking style quadrant (showing that the student prefers that quadrant), the higher the inclination of that score towards the identified option presented by the Likert scale.

The second part of the questionnaire consisted of open-ended questions inviting students to add general comments regarding their overall experience of the lecture. The data were processed by means of a content analysis using Atlas.ti.

The lecturers also recorded their observations of the lecture by completing a SWOT analysis (Morrison, 2005) of the collaborative teaching approach as they experienced it during the lecture.

The TSQ data-collection questionnaire and SWOT analysis all contributed to the results of the case study.

\section{Results and discussion of results}

The results of this paper are described in three parts. The first part provides the results relating to the lecturers prior to the lecture and the extent to which they met the selection criteria, as described in Phase I of the research approach. The second part reports on the results relating to the TSQ prior to the lecture (see Phase II of the research approach). The third part discusses the results of the data-collection questionnaire completed by the students and the SWOT analysis completed by the lecturers after the lecture (see Phase IV of the research approach).

\subsection{The lecturers}

As discussed in Phase I of the research approach, the two chosen lecturers completed the HBDI, for which the results were provided by Herrmann International (Figures 3 and 4).

The profile of Lecturer 1 displays the highest score in the A quadrant and the second highest score in the B quadrant, indicating a preference for A and B quadrant thinking.

The profile of Lecturer 2 displays the highest score in the $\mathrm{C}$ quadrant and the second highest score in the $\mathrm{D}$ quadrant, indicating a preference for $\mathrm{C}$ and $\mathrm{D}$ quadrant thinking.

To determine whether the combined thinking styles of the lecturers represented a strong inclination towards all four quadrants, the average combined scores (Figure 5) were also provided by Herrmann International.

From the results shown in Figure 5, it is evident that the combination of the thinking styles of the two lecturers would theoretically address all the learning preferences of the students, and therefore they met these selection criteria.

The HBDI test was conducted a week prior to the collaborative lecture. The lecturers acknowledged that their thinking styles may have changed, even if only slightly, between the date of the HBDI and the date of the lecture. However, Bunderson (1995, p. 12) found that a person's thinking style can change over time, but that the overall 


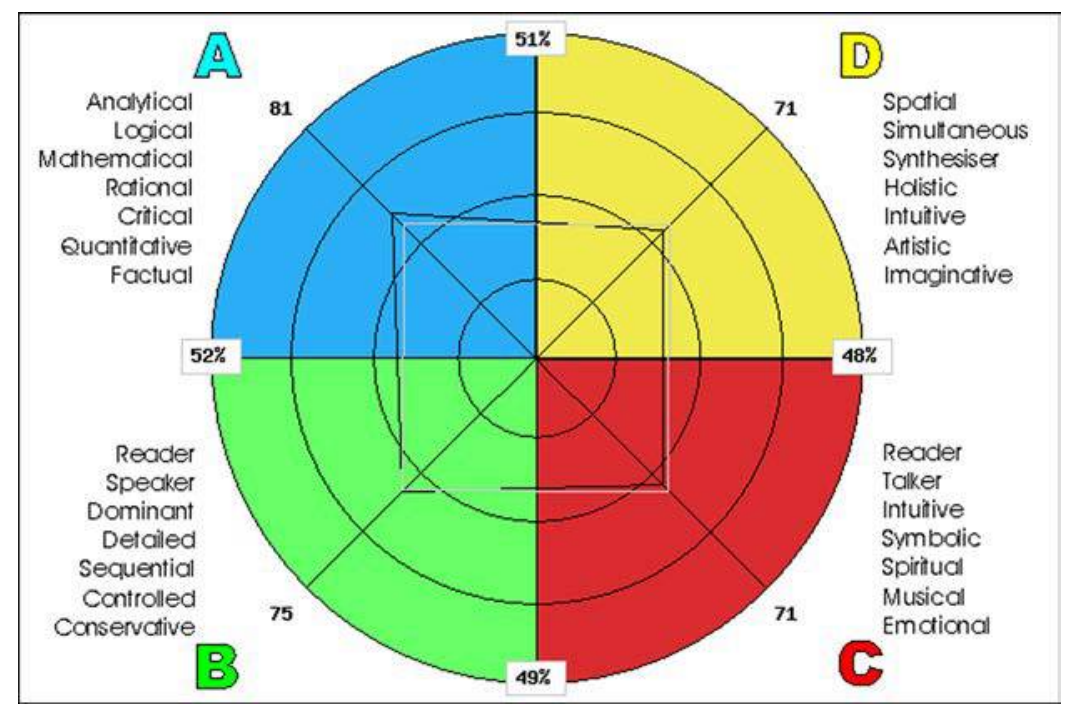

Figure 5. Average combined results of the HBDIs completed by Lecturer 1 and Lecturer 2

patterns appear to be fairly stable. Ho (1988) reported that over 78 repeated measures of the same person, the person's test results were more than 90 per cent similar. Based on this, the researchers concluded that it is unlikely that the short time that elapsed between conducting the test and presenting the lecture could have had a large influence on the results of the study.

To establish whether both lecturers were perceived as equally competent by their students, the results of the previous year's lecturers' evaluations by the students were obtained from the university's IT-Systems department. During the previous academic year, Lecturer 1's average evaluation rating was 4.61 out of 5, and Lecturer 2's rating was 4.64 out of 5 . Therefore, both lecturers seemed to be regarded as about equally competent by their students and they therefore met this selection criterion.

\subsection{The TSQ}

To establish whether the promotion of whole-brain learning was a requirement for the group of students, the thinking styles of the group were determined using the TSQ. However, before the students completed the TSQ, the researchers had to determine whether it was sufficiently accurate for its purpose within the scope and aim of the study. The results of the HBDIs completed by the two lecturers were compared to the results of the TSQ completed by the same two lecturers (Tables I and II).

For Lecturer 1, the results on the HBDI and TSQ were largely similar, with a correlation coefficient of 0.9859 . There was, however, a small deviation in the D

Table I. Comparison of the results of the TSQ and the HBDI completed by Lecturer 1

\begin{tabular}{lcccc} 
Lecturer 1 & A-Quadrant & B-Quadrant & C-Quadrant & D-Quadrant \\
\hline $\begin{array}{l}\text { HBDI (score of 10-150+) } \\
\text { Thinking preference questionnaire }\end{array}$ & 132 & 89 & 23 & 47 \\
(score of 6-30) & 28 & 22 & 12 & 18
\end{tabular}


quadrant score. Largely similar results were also found for Lecturer 2 , with a correlation coefficient of 0.9028 and a small deviation in the A quadrant score. Based on these high correlation coefficients, it was concluded that the TSQ is sufficiently accurate for its purpose within the scope and aim of the study.

The TSQ was completed by the group of students before the lecture commenced. These results, considering only the mean, are presented in the same manner as those of the HBDI, illustrated in Figure 6.

It is evident from Figure 6 that the students as a group represented a balanced distribution of thinking styles, indicating that promoting whole-brain learning was indeed necessary for the group. The distribution of thinking styles is in line with the research conducted by Herrmann (1996) and De Boer et al. (2001), providing further validation for the TSQ.

In this study it is acknowledged that thinking styles cannot be seen as fixed entities, but, based on the prior findings of Bunderson (1995) and Ho (1988), it was assumed to be unlikely that the thinking styles of the students would change significantly from the beginning of the lecture (when the test was conducted) to the conclusion of the lecture (when the questionnaire relating to the lecture and lecturers was completed).

\subsection{Data collected after the lecture}

In the student feedback questionnaire, the student participants were asked to indicate to what extent they agreed [strongly disagreed (SD), disagreed (D), neither agreed nor disagreed $(\mathrm{N})$, agreed $(\mathrm{A})$ or strongly agreed $(\mathrm{SA})]$ with each statement provided.

In interpreting the results, it should be noted that because of the complex variables involved in student-lecturer interactions, the results reported here may have been influenced by factors that were not taken into account in the study, despite attempts to minimise such factors (see Section 6). Thus, some variables beyond the researchers' control may have influenced the results, but the researchers believe that the results give a fair indication of the effectiveness of the student-lecturer interaction.

Table II. Comparison of the results of the TSQ and the HBDI completed by Lecturer 2

\begin{tabular}{lcccc}
\hline Lecturer 2 & A-Quadrant & B-Quadrant & C-Quadrant & D-Quadrant \\
\hline HBDI (score of 10-150+) & 29 & 60 & 119 & 95 \\
$\begin{array}{l}\text { Thinking preference questionnaire } \\
\text { (score of 6-30) }\end{array}$ & 18 & 17 & 27 & 26
\end{tabular}

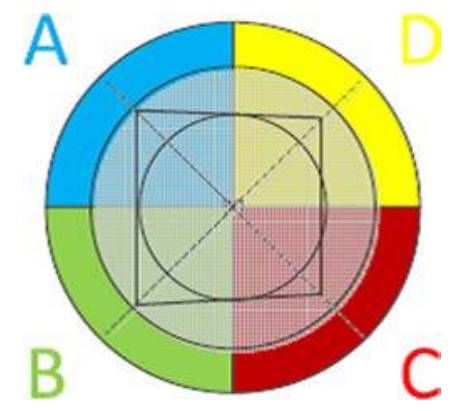

Figure 6. Thinking style profile of group of students 
The results pertaining to the lecture are represented in Table III as a percentage distribution of the group of students. General comments regarding the students' overall experience of the lecture are presented in Table IV (note that the analysis of the qualitative data identified a number of themes and the number of occurrences of any specific theme was calculated; themes with ten or fewer occurrences are not listed).

In respect of the results in Table III, the Kruskal-Wallis test indicates that both the C quadrant and D quadrant scores are aligned to some extent with the choice "agree" and "strongly agree" for the first statement, at the 5 per cent level (a 95 per cent probability). This result seems to indicate that a student with a preference for a $\mathrm{C}$ or D quadrant thinking style was more inclined to find "difficult concepts easier to understand than usual". However, the majority of students (52.75 per cent), irrespective of their thinking style, found "difficult concepts easier to understand than usual" during the lecture.

The Kruskal-Wallis test also indicated that a higher B quadrant score aligned with the choice agreed and strongly agreed with the fourth statement, at the 5 per cent level. This may indicate that a student with a preference for this quadrant was more inclined to experience the "lecture to have a higher energy level than usual lectures of the same module". It is relevant that several prior studies (Buzan, 1991; Jensen, 1996; Knowles, 1990; Ornstein, 1997) suggest that facilitating whole-brain learning results in higher thinking-related energy levels in the classroom. The findings on this statement, together

Table III. Results pertaining to lecture

\begin{tabular}{lccccc} 
Statement & $\mathrm{SD}(\%)$ & $\mathrm{D}(\%)$ & $N(\%)$ & $\mathrm{A}(\%)$ & $\mathrm{SA}(\%)$ \\
\hline $\begin{array}{l}\text { 1. Difficult concepts were easier to understand } \\
\text { than usual during the lecture }\end{array}$ & 7.14 & 16.48 & 23.63 & 38.46 & 14.29 \\
$\begin{array}{l}\text { 2. I have a better understanding of the revision } \\
\text { topics that were dealt with in the lecture }\end{array}$ & 3.85 & 12.64 & 28.57 & 38.46 & 16.48 \\
$\begin{array}{l}\text { 3. I have a good understanding of the new topics } \\
\quad \text { that I did not have any prior knowledge of }\end{array}$ & 3.3 & 7.69 & 27.47 & 45.60 & 15.93 \\
$\begin{array}{l}\text { 4. I found the lecture to have a higher energy } \\
\quad \text { level than the usual lectures of the same } \\
\quad \text { module }\end{array}$ & & & & & \\
$\begin{array}{l}\text { 5. I found it easy to concentrate during the } \\
\quad \text { lecture }\end{array}$ & 13.3 & 10.44 & 18.13 & 35.71 & 32.42 \\
$\begin{array}{l}\text { 6. I found the constant switching between } \\
\text { lecturers to be distracting }\end{array}$ & 13.74 & 25.82 & 18.13 & 29.67 & 12.64 \\
\end{tabular}

Table IV. General comments regarding the participants' overall experience of the lecture

Theme

No. of occurrences

Found the lecture interesting

Different from usual lectures

Found the constant switch between lecturers distracting

It was a positive experience

Enjoyed the lecture

Found the lecture informative

Found it difficult to concentrate

Lecture had good energy

Better understanding of topics 
with the results shown in Table IV and Table VI, show that the students perceived the lecture to have a high energy level. The Kruskal-Wallis test did not indicate any relationship between a disagreement with the fourth statement and any of the thinking styles of the students, indicating that the majority of students (68.13 per cent), irrespective of their thinking styles, thought that the lecture had a higher energy level than other lectures in the same series.

The literature (Buzan, 1991; Jensen, 1996; Knowles, 1990; Ornstein, 1997) also suggests that facilitating whole-brain learning may result in a better understanding of content. The findings relating to Statements 1 to 3 and also those reported in Table IV suggest that, to some extent, students had a better understanding of difficult concepts, revision topics and new topics at the end of the lecture. The Kruskal-Wallis test established that there is no relationship between any of the quadrants and a disagreement with Statements 1 to 3 . This may suggest that every student, irrespective of his or her thinking style and learning preference, was likely to agree or strongly agree with these statements. Based on this, it seems likely that most of the learning preferences of the students were accommodated and, consequently, this may support the notion of promoting whole-brain learning.

Although it seems that the collaborative teaching approach was mostly positively received by the students, the results do raise some concerns. Statements 5 and 6 and the results shown in Table IV indicate that a large percentage of the students found the constant switching between the lecturers distracting (38.47 per cent), and also found it difficult to concentrate during the lecture (39.56 per cent). These results reflect negatively on the use of a collaborative teaching approach. Further research is needed to determine whether an adjustment period for students to a collaborative teaching approach could influence these results.

The results pertaining to the lecturers are represented in Table $\mathrm{V}$ as a percentage distribution of the group of students.

In respect of the results set out in Table V, the Kruskal-Wallis test indicates a relationship between the A quadrant score and agreement with Statements 7 and 9, at

Table V. Results pertaining to lecturers

Statement

$\mathrm{SD}(\%)$

$\mathrm{D}(\%)$

$N(\%)$

$\mathrm{A}(\%) \quad \mathrm{SA}(\%)$

7. I found that the first lecturer lectured in a manner that I prefer 6.6

8. I found that the second lecturer lectured in a manner that I prefer

9. I found the lecturing style of the first lecturer interesting

10. I found the lecturing style of the second lecturer interesting

11. I found that the lecturers made a good team

12. If I was unable to understand a topic after one lecturer had explained it, the other lecturer assisted me in understanding the topic better

$\begin{array}{rrrrr}6.6 & 12.6 & 23.6 & 29.7 & 27.5 \\ 7.1 & 18.7 & 25.8 & 31.3 & 17.0 \\ 4.4 & 12.6 & 20.9 & 44.0 & 18.1 \\ & & & & \\ 2.8 & 9.3 & 28.0 & 42.3 & 17.6 \\ 5.5 & 6.0 & 18.7 & 41.8 & 28.0 \\ & & & & \\ 5.0 & 9.9 & 24.5 & 38.5 & 19.2 \\ & & & & \\ 30.7 & 15.9 & 22.5 & 15.9 & 14.8\end{array}$

13. I would prefer to be lectured by two lecturers (jointly as in the current lecture) in future

15.9 
the 5 per cent level. These results suggest that students with an A quadrant thinking style and learning preference also preferred Lecturer 1, who tends to adopt an A quadrant thinking and teaching style. This result seems to support Herrmann's claims regarding the relationship between thinking style, teaching style and learning preference to some extent, and also corroborates the validity of the methodology chosen for this study.

In line with the findings discussed in the previous paragraph (although to a lesser extent), a relationship was found between the $\mathrm{C}$ quadrant score and agreement with Statement 10, at the 5 per cent level. This seems to indicate that a student with a $\mathrm{C}$ quadrant thinking style and learning preference is more inclined to find a lecturer who has a $\mathrm{C}$ quadrant thinking and teaching style more "interesting". This reinforces the claim to validity for the methodology adopted in the research.

The results for Statement 11 seem to suggest that the majority of students (69.8 per cent) perceived the lecturers to be a good team. This may support the selection of team teaching as a collaborative teaching model for the research.

Despite the largely positive results, responses to Statement 13 seem to indicate that many students (46.6 per cent) would prefer the collaborative teaching approach not to be used in future. Investigating the reasons for this result was beyond the scope of this study.

As discussed in Phase IV of the research approach, the lecturers completed a SWOT analysis after the lecture. The results are listed in Table VI.

The results of the SWOT analysis seem to support some of the results in Table III, and indicate a higher level of student engagement compared to that experienced by the lecturers in other lectures. The analysis also suggests some additional benefits of the collaborative teaching approach, such as lecturers combining their knowledge and thereby also learning from one another with regard to content and teaching style. The SWOT analysis also suggests some threats and weaknesses, such as the lectures being time-consuming and resource-intensive, and the sense of a loss of some control over the lecture and the amount of knowledge transferred.

The results suggest that, first, it is likely that the collaborative teaching approach was effectively applied by the lecturers; second, that such an approach may promote whole-brain learning among students; and, third, that the approach poses a challenge to students in respect of maintaining their concentration during the lecture.

Table VI. Results of SWOT analysis completed by lecturers

\begin{tabular}{ll}
\hline Strengths & Weaknesses \\
\hline $\begin{array}{l}\text { Constant change in energy } \\
\text { Participants more engaged } \\
\text { Combined knowledge }\end{array}$ & $\begin{array}{l}\text { Time-consuming } \\
\text { Wanting to talk at the same time } \\
\text { Less amount of control over lecture }\end{array}$ \\
\hline Opportunity & Threats \\
\hline $\begin{array}{l}\text { Good learning experience for lecturers } \\
\text { Improved understanding of content by lecturers }\end{array}$ & $\begin{array}{l}\text { Resource consumption } \\
\text { Resistance to change from students } \\
\text { Excessive knowledge transferred }\end{array}$
\end{tabular}




\section{Conclusion}

Changing teaching styles to accommodate the variety of learning preferences of students presents a great challenge to lecturers. The thinking style of a lecturer relates directly to the lecturer's preferred teaching style (Herrmann, 1989). A possible mismatch can therefore arise between a lecturer's teaching style and students who have a different thinking style (and consequently learning preference) to the lecturer. To address this mismatch, this paper set out to determine whether team teaching by two criteria-specific lecturers can be an effective collaborative teaching approach that can accommodate the diverse learning preferences of students, resulting in whole-brain learning.

Collaborative teaching, a teaching approach most commonly adopted as a service delivery option in special education (Adams and Cessna, 1991), has thus far received very little attention as a teaching approach within a general education context. To apply a collaborative teaching approach and to combine the thinking styles of the lecturers who collaborated as effectively as possible, a team teaching model to collaborative teaching was adopted. This model provides for shared instruction to a single group of students (in other approaches, one instructor may act as a leader, or more than one group of students may be taught).

The results of this study support the findings in the prior literature that every group of students will represent a fairly equal spread of thinking styles (De Boer and Berg, 2001; De Boer et al., 2001; Herrmann, 1996; Shelnutt et al., 1996). The paper also provides some support for Herrmann's (1989) finding that a lecturer tends to adopt a teaching practice in line with his or her thinking style, and that students with a similar thinking style will prefer that lecturer to another lecturer who has a different thinking style. Finally, the paper provides some insight on the use of a collaborative teaching approach within a general education context.

Further research needs to be conducted to identify the effects of implementing a collaborative teaching approach on a continuing basis, but the results presented here already suggest that a collaborative teaching approach could potentially promote whole-brain learning among students. It is acknowledged that constant switching between lecturers could be distracting, although the fact that the switching was distracting to this group of students may be ascribed to the students not being used to alternative approaches. A new transformative learning culture should be introduced and nurtured. The human resource consumption of a collaborative teaching approach could be an aspect that might engender resistance from institutions to applying this teaching approach in practice, but this approach seems useful in accommodating the diverse learning preferences of students.

In conclusion, the paper provides some evidence in support of combining teaching efforts, although such an approach should be adopted with care in both the selection of the lecturers who are to collaborate and the implementation of such an approach. Lecturers should be made more aware of the benefits, limitations and challenges that could arise in adopting a collaborative teaching approach.

\section{References}

Adams, L. and Cessna, K. (1991), "Designing systems to facilitate collaboration: collective wisdom from Colorado”, Preventing School Failure, Vol. 35 No. 4, pp. 37-42.

Bauwens, J., Hourcade, J.J. and Friend, M. (1989), "Cooperative teaching: a model for general and special education integration”, Remedial \& Special Education, Vol. 10 No. 2, pp. 17-22. 
Bawaneh, A.K., Zain, A.N. and Saleh, S. (2010), 'Investigating tenth grade Jordanian students' thinking styles based on Herrmann's Whole Brain Model for the purpose of developing new teaching method in modifying science misconceptions", Educational Research, Vol. 1 No. 9, pp. 363-372.

Bunderson, C.V. (1995), “The validity of the Herrmann Brain Dominance Instrument”, available at: www.hbdi.co.za/documents/Validation.pdf (accessed 20 April 2012).

Buzan, T. (1991), Use Both Sides of your Brain, 3rd ed., Plume, New York, NY.

Coffield, F., Moseley, D., Hall, E. and Ecclestone, K. (2004), "Learning preferences and pedagogy in post-16 learning: a systematic and critical review", available at: http://sxills.nl/lerenlerennu/ bronnen/Learning\%20styles \%20by\%20Coffield\%20e.a..pdf (accessed 15 May 2012).

Cook, L. and Friend, M. (1995), “Co-teaching: guidelines for creating effective practices”, Focus on Exceptional Children, Vol. 28 No. 3, pp. 1-16.

Curry, L. (1991), "Patterns of learning preference across selected medical specialities", Educational Psychology, Vol. 11 Nos 3/4, pp. 247-277.

De Boer, A. and Berg, D. (2001), "The value of the Herrmann Brain Dominance Instrument in facilitating effective teaching and learning of criminology", Acta Criminologica, Vol. 14 No. 1, pp. 119-129.

De Boer, A. and Bothma, T. (2003), "Thinking styles and their role in teaching and learning”, paper presented at the 24th IATUL Conference, Ankara, 2-5 June, available at: www.iatul.org/ doclibrary/public/conf_proceedings/2003/deboer_fulltext.pdf (accessed on 30 June 2012).

De Boer, A. and Steyn, T. (1999), "Thinking style preferences of underprepared first year students in the natural sciences", South African Journal of Ethnology, Vol. 22 No. 3, pp. 97-102.

De Boer, A., Steyn, T. and Du Toit, P.H. (2001), "A whole brain approach to teaching and learning in higher education", South African Journal of Higher Education, Vol. 15 No. 3, pp. 185-193.

Dunn, R. and Dunn, K. (1979), "Learning preferences/teaching styles: should they [...] can they [...] be matched?”, Educational Leadership, Vol. 36 No. 4, pp. 238-245.

Dunn, R. and Griggs, S.A. (1988), Learning Preferences: A Quiet Revolution in American Secondary Schools, National Association of Secondary School Principals, Reston, VA.

Fuchs, D. and Fuchs, L.S. (1992), "Limitations of a feel-good approach to consultation", Journal of Educational and Psychological Consultation, Vol. 3 No. 2, pp. 93-98.

Gardner, H. and Hatch, T. (1989), "Multiple intelligences go to school: educational implications of the theory of multiple intelligences", Educational Researcher, Vol. 18 No. 8, pp. 4-10.

Gerber, P.J. and Popp, P.A. (2000), "Making collaborative teaching more effective for academically able students", Recommendations for Implementation and Training. Learning Disability Quarterly, Vol. 23 No. 3, pp. 229-233.

Geschwind, N. and Galaburda, A.M. (1987), Cerebral Lateralisation: Biological Mechanisms, Associations and Pathology, MIT Press, Cambridge, MA.

Grigorenko, E.L. and Sternberg, R.J. (1995), “Thinking styles”, in Saklofske, D.H and Zeidner, M. (Eds), International Handbook of Personality and Intelligence, Plenum, New York, NY, pp. 205-231.

Herrmann, N. (1989), The Creative Brain, Brain Books, Lake Lure, NC.

Herrmann, N. (1995), The Creative Brain, 2nd ed., Quebecor Printing Book Group, Kingsport, TN.

Herrmann, N. (1996), The Whole Brain Business Book, McGraw Hill, New York, NY. 
Herrmann, N. (1998), "Twenty years of thinking about the thinking brain: a special summary of learning outcomes”, Unpublished document, Herrmann International, Lake Lure, NC.

Heywood, J. (1874), The Proverbs of John Heywood, Bell, London.

Ho, K.T. (1988), "The dimensionality and occupational discriminating power of the Herrmann Brain Dominance Instrument", Unpublished dissertation, Brigham Young University, Provo, UT.

Howell, P. (1991), “Taking AIM to assist middle school students with special needs”, Preventing School Failure, Vol. 35 No. 4, pp. 43-47.

Hyman, R. and Rosoff, B. (1984), "Matching learning and teaching styles: the jug and what's in it", Theory into Practice, Vol. 23 No. 1, pp. 35-43.

Jackson, C. (2002), "Manual of the learning preferences profiler", available at: www.cymeon.com/ 1ss2.asp (accessed 10 September 2013).

Jensen, E. (1996), Brain-Based Learning, Turning Point, San Diego, CA.

Jung, C.G. (1968), Analytical Psychology: Its Theory and Practice - the Tavistock Lectures, Random House, New York, NY.

Kagan, J. (1966), "Reflection-impulsivity: the generality and dynamics of conceptual tempo", Journal of Abnormal Psychology, Vol. 71 No. 1, pp. 17-24.

Knowles, M. (1990), The Adult Learner: A Neglected Species, 4th ed., Gulf Publishing, Houston, TX.

Kolb, D.A. (2000), Facilitator's Guide to Learning, Hay/McBer, New York, NY.

Messick, S. (1984), "The nature of cognitive styles: problems and promise in educational practice", Educational Psychologist, Vol. 19 No. 2, pp. 59-74.

Morrison, M. (2005), "SWOT Analysis", available at http://rapidbi.com/swotanalysis/ (accessed 18 January 2012).

Myers, I.B. and McCaulley, M.H. (1985), Manual: a Guide to the Development and Use of the Myers-Briggs Type Indicator, Consulting Psychologists Press, Palo Alto, CA.

Ornstein, R. (1997), The Right Mind: Making Sense of the Hemispheres, Harcourt Brace, New York, NY.

Pugach, M.C. and Johnson, L.J. (1995), Collaborative Practitioners, Collaborative Schools, Love Publishing, Denver, CO.

Reeve, P.T. and Hallahan, D.P. (1994), "Practical questions about collaboration between general and special educators", Focus on Exceptional Children, Vol. 26 No. 7, pp. 1-11.

Robinson, B. and Robert, M. (1995), "Collaborative teaching: reaping the benefits", College Teaching, Vol. 43 No. 2, pp. 57-59.

Robson, C. (2011), Real World Research: A Resource for Users of Social Research Methods in Applied Settings, 3rd ed., Wiley-Blackwell, Oxford.

Shelnutt, J., Middleton, S., Buch, K. and Lumsdain, M. (1996), "Forming student project teams based on Herrmann Brain Dominance (HBDI) Results", paper presented at the ASEE Annual Conference, Washington, DC, June 22-24, available at: http://search.asee.org/search/ fetch;jsessionid=3apilkectl01f?url =file $\% 3 \mathrm{~A} \% 2 \mathrm{~F} \% 2 \mathrm{Flocalhost} \% 2 \mathrm{FE} \% 3 \mathrm{~A} \% 2 \mathrm{Fsearch}$ $\% 2 \mathrm{Fconference} \% 2 \mathrm{~F} 20 \% 2 \mathrm{FAC} \% 25201996 \mathrm{Paper} 185$.pdf\&index $=$ conference_papers\&space $=$ $129746797203605791716676178 \&$ type $=$ application $\% 2$ Fpdf\&charset $=$ (accessed 20 February 2013).

Slabbert, J.A., De Kock, D.M. and Hattingh, A. (2009), The Brave "New" World of Education: Creating a New Professionalism, Juta, Cape Town.

Springer, S.P. and Deutsch, G. (1989), Left Brain, Right Brain, Freeman, New York, NY. 
Trigwell, K., Prosser, M. and Waterhouse, F. (1999), "Relations between teachers' approaches to teaching and students' approaches to learning”, Higher Education, Vol. 37 No. 1, pp. $57-70$.

Walsh, J.M. (1992), "Student, teacher, and parent preference for less restrictive special education models - cooperative teaching", Case in Point, Vol. 6 No. 2, pp. 1-12.

White, A.E. and White, L.L. (1992), "A collaborative model for students with mild disabilities in middle schools”, Focus on Exceptional Children, Vol. 24 No. 9, pp. 1-10.

Witkin, H.A. (1962), Psychological Differentiation: Studies of Development, Wiley, New York, NY.

Wood, D.J. (1991), “Aspects of teaching and learning”, in Light, P., Sheldon, S. and Woodhead, M. (Eds), Learning to Think, Routledge, New York, NY, pp. 97-121. 